\title{
O capital comercial e a formação da economia-mundo capitalista: dinâmica e padrões de reprodução social ${ }^{1}$
}

\author{
Eduardo Barros Mariutti \\ Instituto de Economia / Universidade Estadual de Campinas (IE/UNICAMP)
}

Recebido: 11/12/2019 Versão revisada (entregue): 22/02/2020 Aprovado: 06/03/2020

\begin{abstract}
Resumo
Até consolidar-se a Revolução Industrial, era o capital comercial que pairava sobre a base produtiva da economia-mundo capitalista. Ele articulava pelo alto as diversas formas de producão dispersas pela Europa pré-industrial e definia o papel complementar das regiões articuladas ao continente. Dado que, de maneira geral, o capital fixo exercia um papel limitado no processo de produção, a reprodução da economia-mundo dependia, em grande parte, do capital circulante que, na era mercantilista, representava a forma predominante assumida pelo capital mercantil. Então, que contribuição daria o capital comercial para a formação da economia-mundo capitalista? O propósito, aqui, é precisamente o de examinar essa questão. As evidências indicam que o modo de produção capitalista acabaria deslocando para os bastidores as formas tradicionais de controle da sociedade sobre o "mercado", incluindo-se aí os sistemas redistributivos, as estruturas de parentesco, a religião e a magia. A hipótese é de que esse deslocamento pode ser desvelado por um exame cuidadoso dos mecanismos e formas de reprodução do capital mercantil, enfim, das vias que facultaram a sua penetração na sociedade.
\end{abstract}

Palavras-chave | Capital comercial; capital mercantil; economia-mundo capitalista; mercantilismo.

Código JEL | F02 N13 P19

Commercial capital and the formation of the capitalist world-economy: dynamics and patterns of social reproduction

\begin{abstract}
Until the Industrial Revolution be consolidated, it was the commercial capital that hovered over the productive bases of the capitalist world-economy. It not only articulated different forms of

\footnotetext{
${ }^{1}$ Uma versão inicial deste artigo foi publicada, sob o título "Capital comercial autônomo: dinâmica e padrões de reprodução", como "Texto para Discussão" [N. 214] junto ao Instituto de Economia, da Unicamp, em dezembro de 2012.
} 
production spread throughout preindustrial Europe from the top, but also shaped the complementary role of regions integrated to the continent. Given that, in the Age of Mercantilism, the fixed capital exercised limited role in the production process. The reproduction of the world-economy was, in large part, dependent of the circulating capital, which represented the predominant form assumed by the merchant capital. So, which was the commercial capital contribution to the formation of the capitalist world-economy? The aim of this paper is to explore this question. Evidences suggest that the capitalist mode of production would eventually shift to behind the scenes traditional forms of social control over the "market", including redistribute systems, kinship structures, religion, and magic. The hypothesis states that this shifting could be unveiled by a carefully examine of the mechanisms and forms of reproduction of the merchant capital, focus the ways which provide its penetration into the societies.

Keywords | Commercial capital; merchant capital; capitalist world-economy; mercantilism.

JEL-Code | F02 N13 P19

\section{Capital comercial y la formación de la economía-mundo capitalista: dinámicas y patrones de reproducción social}

\section{Resumen}

Hasta que se consolidó la Revolución Industrial, fue el capital comercial lo que flotaba sobre las bases productivas de la economía-mundo capitalista. Este articuló diferentes formas de producción dispersas por toda la Europa preindustrial y dio forma al papel complementario de las regiones integradas al continente. De manera general, el capital fijo ejerció un papel limitado en el proceso de producción, la reproducción de la economía-mundo dependía, en gran parte, del capital circulante que, en la era mercantilista, representaba la forma predominante asumida por el capital mercantil. Entonces, ¿cuál fue la contribución de capital comercial a la formación de la economía-mundo capitalista? El objetivo aquí es explorar esta cuestión. Las evidencias sugieren que el modo de producción capitalista terminaría desplazando para los bastidores las formas tradicionales de control de la sociedad sobre el "mercado", incluyendo sistemas de redistribución, estructuras de parentesco, religión y magia. La hipótesis afirma que este cambio podría ser revelado por un examen cuidadoso de los mecanismos y formas de reproducción del capital mercantil, en resumen, de las formas que permitieron su penetración en la sociedad.

Palabras clave | capital comercial; capital mercantil; economía-mundo capitalista; mercantilismo.

Codigo JEL | F02 N13 P19

\section{Introdução}

Até a consolidação da Revolução Industrial, era o capital comercial que pairava sobre a base produtiva da economia-mundo capitalista: ele articulava pelo alto as 
diversas formas de producão dispersas pela Europa pré-industrial e definia o papel complementar das regiões articuladas ao continente. Como, de um modo geral, o capital fixo exercia um papel muito pequeno no processo de produção, a reprodução da economia-mundo dependia, em grande parte, do capital circulante que, na era mercantilista, representava a forma predominante assumida pelo capital mercantil ${ }^{2}$. Assim, nestas condições peculiares, a grande disponibilidade de recursos em dinheiro era crucial: a riqueza permitia aos grandes mercadores explorar um amplo e variado leque de investimentos e, o que é mais importante, manter propositalmente uma relação indireta e oblíqua com a "produção". A sua ação principal ocorria nas intersecções entre sistemas econômicos distintos, preferencialmente envolvendo civilizações diferentes ${ }^{3}$, operando com metais preciosos e outros bens de consumo suntuoso. Depois da grande crise do século $\mathrm{XIV}$, as tentativas de reorganização da sociedade feudal abriram novas frentes como, por exemplo, atender à cobiça dos privilegiados, cada vez mais aguçada pelo luxo e o esplendor da vida cortesã europeia em constituição. E, até mesmo, penetrar mais intensamente nas cidades, fato que, no futuro, viabilizou a articulação do campo ao movimento do capital comercial (ANDERSON, 1974; MERRINGTON, 1975; POLANYI, 2000). Por fim, era possível também explorar a avidez pelo bullion por parte dos Estados mercantilistas em intensa rivalidade. Portanto, a resistência dos grandes detentores de riqueza à especialização e aos investimentos na produção não são traços de uma mentalidade aristocrática arcaica ou anacrônica, mas, sim, de um comportamento perfeitamente ajustado às condições vigentes na era onde dominava a acumulação primitiva de capitais.

\footnotetext{
2 Fernand Braudel partindo de uma perspectiva muito diferente do materialismo histórico e baseando-se na controversa dicotomia capitalismo/não-capitalismo, afirma: "Capitalism, having been identified as the realm of investimento and of a high rate of capital formation, must next be related to economic life, with which it was not entirely coterminous. There are thus two zones in which it can be located: its native soil so to speak, the sector in which it was completely at home; and another sector which it entered only obliquely, insinuating itself into this zone without ever completely dominating it. Until the industrial revolution of the nineteenth century, when capital moved into industrial production, now newly-promoted to the rank of large profit-maker, it was in the sphere of circulation, trade and marketing that capitalism was most at home; even if it was not concerned with the whole of circulation, since it only controlled, or sought to control, certain channels of trade" (1982, p. 231-2). Capitalismo, no entender de Braudel, não é sinônimo de capital comercial, mas, do modo como o trataremos, ele pode ser concebido como uma de suas manifestações principais, isto é, por partir de redes de privilégio incrustradas na cúpula das sociedades que medeia. O capital comercial opera como um sistema de exploração destinado a falsear sistematicamente as relações de um hipotético mercado autorregulável. Esse é, simultaneamente, o ponto mais forte e mais fraco de Braudel. Forte, pois adiciona a necessidade de compreender a constituição do capitalismo levando em conta as hierarquias políticas e simbólicas da sociedade, mediante a comparação entre as "civilizações". Mais fraco, pois tem como base o pressuposto que uma economia de mercado "transparente" - e baseada na troca de equivalentes - emerge naturalmente de qualquer sociedade que ultrapasse o limite da subsistência. Logo, se fosse possível livrar-se do capitalista - o falseador das trocas, cuja expressão máxima é o comerciante de dinheiro - o mercado "justo" se estabeleceria quase automaticamente. (CAILLÉ, 1989, p. 103-7; 110-4; 119-21). Não por acaso, é nítida a simpatia de Braudel por Proudhon e, provavelmente, jamais se oporia a estilo de reflexão destinada a promover a eutanásia do rentista.

3 Sobre o modo como estas interações ocorreram ao longo do tempo e, especialmente depois da "revolução marítima do século XV", ver o excelente livro de Peter Curtin (1984). Convém também consultar Karl Polanyi (1971a).
} 
Logo, a característica fundamental deste período é que a producão ainda não era dominantemente capitalista, mas já existia um setor mercantil relativamente desenvolvido. Só que, exatamente por causa do caráter não capitalista da produção, o capital só era capaz de se reproduzir na circulação, amparado nos privilégios sociais e na inequivalência das trocas. Em termos mais simples: a produção era feita para, e não pelo capital. Logo, não é exagero dizer que o capital comercial predomina na esfera da circulação (e a ocupa quase integralmente), e pode até se esforçar para subsumir a produção à sua lógica, mas sem eliminar a separação entre produção $e$ circulação. Marx, buscando demarcar a especificidade do modo de produção capitalista, já havia apontado as características básicas - e praticamente "universais" - do capital mercantil:

Dentro do modo de produção capitalista - isto é, assim que o capital se apoderou da própria produção e lhe deu uma forma completamente alterada e específica - o capital comercial aparece apenas como uma função específica. Em todos os modos anteriores de produção - e tanto quanto mais a produção é produção direta dos meios de subsistência do produtor - o capital comercial aparece como sendo a função par excellence do capital. (MARX, 1988b, p. 233).

A autonomia do capital comercial só é possível, portanto, fora do modo de produção capitalista plenamente constituído ${ }^{5}$, e, nos demais modos de produção, a sua manifestação pressupõe e reforça a separação entre o seu circuito - a circulação e a produção:

A fortuna comercial autônoma, como forma dominante do capital, é a autonomização do processo de circulação contra seus extremos, e esses extremos são os próprios produtores que intercambiam. Esses extremos permanecem autônomos contra o processo de circulação, e esse processo contra eles. $\mathrm{O}$ produto aqui se torna mercadoria pelo comércio. É o comércio que aqui desenvolve a configuração dos produtos que se tornam mercadorias; não é a mercadoria produzida que, com seu movimento, forma o comércio. (MARX, 1988b, p. 234).

\footnotetext{
${ }^{4}$ Em outro momento, em conhecida passagem, ele refina ainda mais a análise: "O capital portador de juros, ou como podemos denominá-lo em sua forma antiga, o capital usurário, pertence, com seu irmão gêmeo, o capital comercial, às formas antediluvianas do capital, que por longo tempo precedem o modo de produção capitalista e se encontram nas mais diversas formações econômicas da sociedade” (MARX, 1988a, p. 97).

5 "Um desenvolvimento autônomo e preponderante do capital enquanto capital comercial equivale à nãosubordinação da produção ao capital, portanto, ao desenvolvimento do capital com base em uma forma de produção "[que]" lhe é estranha e independente dele. O desenvolvimento autônomo do capital comercial é inversamente proporcional ao desenvolvimento econômico geral da sociedade” (MARX, 1988b, p. 234).
} 
Essa passagem é bastante esclarecedora. Quando produzidos em outros modos de produção que não o capitalista, os produtos só se tornam mercadorias quando expropriados - e a forma de espoliação varia, mas ela sempre é, se tivermos como referência o capitalismo, "extraeconômica" - para serem inseridos nos circuitos do capital comercial ${ }^{6}$.

Em outro momento, ao criar o conceito de subsunção formal do trabalho à produção, Marx apontou a situação limite do capital mercantil: após um certo nível de acumulação, o capital comercial invade a produção de forma extensiva, orientando-a para o lucro, mas sem promover transformações qualitativas no processo de trabalho:

O processo de trabalho converte-se no instrumento do processo de valorização, do processo da autovalorização do capital: da criação da mais-valia. O processo de trabalho subsume-se no capital (é o processo do próprio capital), e o capitalista entra nele como dirigente, guia; para este é ao mesmo tempo, de maneira direta, um processo de exploração do trabalho alheio. É isto que denomino subsunção formal do trabalho no capital. É a forma geral de qualquer processo capitalista de producão, é, porém, simultaneamente, uma forma particular em relação ao modo de produção especificamente capitalista desenvolvido, já que o último inclui a primeira, porém a primeira não inclui necessariamente o segundo. (MARX, s/d, p. 87 grifo meu).

Logo, o momento que precede imediatamente a consolidação da indústria moderna é marcado pela subsunção formal do trabalho ao capital. A diretriz básica é a produção de mais-valia absoluta por meio da expansão da jornada de trabalho, do recrutamento de uma faixa mais ampla de proletários (mulheres e crianças) e da multiplicação das unidades produtivas, mas que, essencialmente, repousa sobre a extensão dos processos de trabalho preexistentes (Marx chega a empregar recorrentemente o termo "tradicionais").

No caso acima descrito, o capital mercantil ainda domina os circuitos superiores das trocas e já se insinua sobre o resto da vida econômica. A peculiaridade é que seus vínculos com a produção se tornam mais diretos e, essencialmente, perenes. Entretanto, a produção não se encontra plenamente subordinada ao capital. Logo, a compreensão da formação do modo de produção capitalista exige uma caracterização precisa da forma econômica que precedeu o capitalismo dito “industrial". É o que faz, por exemplo, Fernando Novais, ao definir o período como uma economia mercantil simples, com acumulação primitiva de capital comercial

\footnotetext{
${ }^{6}$ Sua autonomia é pensada aqui, essencialmente, como uma contraposição ao capital que, no capitalismo (a rigor, só há capital em termos marxianos neste modo de produção) não pode ser pensado sem a sua tensão com o trabalho. A reprodução do capital comercial, portanto, independe da reprodução das formas de trabalbo em que se apoia. Por isso está sempre fadado a mediar circuitos econômicos ou formações sociais em que não consegue penetrar radicalmente. Em outros termos: a circulação é o seu principal espaço de atuação.
} 
autônomo (NOVAIS, 2005). Uma economia com estas características não possui uma lógica exclusivamente econômica, pois, por conta do elevado grau de autarquia das unidades produtivas e dos mercados locais, a indução ao desenvolvimento em um sentido capitalista é extraeconômica e, em grande parte, foi empreendida pelos Estados em seu esforço de consolidação do seu poder no "seu" território e na correlata luta pela preponderância na Europa, em meio a uma intensa disputa - e transformação - das forças sociais pelo poder local, pela posse da terra e demais meios de produção. É exatamente a tensão entre imensas zonas ainda autárquicas e um circuito mercantil ligado predominantemente aos metais preciosos e ao consumo suntuoso que permitia a sobrevivência de valores nobiliárquicos e tornava o investimento em cargos de prestígio uma alternativa segura para os detentores de riqueza. Estabelecidos estes marcos mais gerais, resta agora demarcarmos melhor os mecanismos de reprodução do capital comercial durante o Antigo Regime.

\section{Os padrões de reprodução do capital comercial no âmbito de uma economia-mundo em formação}

Entre os séculos XVI e XVIII, a nascente economia-mundo moderna era articulada pela rivalidade política entre os Estados em formação $e$ pelas teias do capital mercantil. No caso deste, nos primórdios, o entrelaçamento inicial era tênue e se dava essencialmente pelo cume, isto é, em torno do consumo conspícuo. Progressivamente algumas transformações que operavam na base - i.é. as respostas locais à crise do século XIV, estruturadas pela luta de classes (a temática do "debate sobre a transição") - possibilitaram com que a rede de transações do capital mercantil alinhavasse indiretamente os polos manufatureiros. Estes começaram a surgir em algumas regiões da Europa Ocidental ${ }^{7}$, articulando as Américas, porções da África e a Europa Oriental, fato que acabou por gerar um vínculo entre as transformações operadas nestas regiões. Enquanto o centro em constituição tendia para a produção baseada na manufatura e nos pequenos produtores independentes, a periferia e a semiperiferia tendiam para a especialização no fornecimento de matérias primas e gêneros alimentícios, com base no trabalho compulsório. Logo, o tipo de produção tendeu a se vincular com a

\footnotetext{
7 Ao contrário do que sugerem os adeptos da "proto-indústria" — Franklin Mendels (1972) mas, sobretudo, Peter Kriedte (1984) - a manufatura (e as raríssimas fábricas) era o ponto terminal de uma difusa rede que começava nas oficinas (corporações de ofício e a produção artesanal domiciliar ou aldeã), entremeava-se no Verlagsystem (Putting out) e culminava na manufatura. Esta não se reproduzia endogenamente, não por causa da falta de trabalho livre (este era um potencial fator limitante, mas não era o essencial), mas, sobretudo, porque o homem com a habilidade de manejar as ferramentas, imprescindível para o acabamento da mercadoria, era gerado nas corporações de oficio que, por conta de suas peculiaridades, estava à margem do mercado em um sentido capitalista. O golpe definitivo sobre esta forma de resistência é dado com a generalização da máquina-ferramenta [working machine] que, ao adquirir a habilidade de manipular ferramentas, incorporou os saberes dos artesãos.
} 
forma de controle sobre o trabalho e com o sistema político local. Immanuel Wallerstein destacou este ponto com clareza:

\begin{abstract}
"Why different modes of organizing labor - slavery, 'feudalism', wage labor, self employment - at the same point in time within the world- economy? Because each mode of labor control is best suited for particular types of production. And why were these modes concentrated in different zones of the worldeconomy -slavery and 'feudalism' in the periphery, wage labor and self-employment in the core, and as we shall see sharecropping in the semiperiphery? Because the modes of labor control greatly affect the political system (in particular the strength of the state apparatus) and the possibilities for an indigenous bourgeoisie to thrive. The world-economy was based precisely on the assumption that there were in fact these three zones and that they did in fact have different modes of labor control. Were this not so, it would not have been possible to assure the kind of flow of the surplus which enabled the capitalist system to come into existence" $(1974, \text { p. } 87)^{8}$.
\end{abstract}

Esta rede complexa de relações, em grande parte articulada, mas também sobreposta, é que garantia a autonomia do capital comercial com relação à esfera da produção.

Como já indiquei, o detentor do capital mercantil encontrava uma grande variedade de oportunidades. Podia emprestar dinheiro às vorazes máquinas de Estado - cada qual com composições sociais internas variadas - em intensa competição, financiar a distância atividades essenciais tais como, por exemplo, a mineração e a construção naval. E, principalmente, podia fugir do investimento em capital fixo: este ficava a cabo dos pequenos produtores independentes nas nascentes manufaturas, dos colonos no caso das Américas (proprietários dos Latifúndios e engenhos, que eram obrigados a imobilizar a maior parte de seu parco capital) e dos "magnatas feudais" na Europa Oriental, produtores de gêneros alimentícios. A concentração dos fatores de produção nas mãos de uma reduzida elite, em conjunto com a predominância quase absoluta do trabalho compulsório estrangulava os mercados locais ${ }^{9}$ na periferia, fato que estimulava a orientação para as redes do capital mercantil mediante uma pauta de exportações muito restrita: metais preciosos e produtos primários fundamentalmente ${ }^{10}$. A tendência era

\footnotetext{
${ }^{8}$ Esta é uma breve descrição do movimento geral, nítido apenas em retrospectiva. Wallerstein sempre insistiu que a formação do capitalismo não foi um resultado inevitável da crise do feudalismo. Muito pelo contrário: o longo século XVI foi um período tenso exatamente porque surgiram diversas possibilidades de transformação. Mas isto não evita um problema teórico inerente a toda visão baseada em algum grau de determinismo: o padrão de comparação é o futuro do período em análise. Este aspecto, perigosa não necessariamente anacrônico, domina a análise de Wallerstein (e de Braudel, bem como da esmagadora maioria da tradição marxista). O sentido básico e a dinâmica da economia-mundo se revela com a sua consolidação, e isto conduz o peso relativo dos elementos na explicação (e torna-se o critério para julgar o que é relevante ou não para se estudar), fato que abre outro problema: quando? Ou melhor, que critério podemos usar para afirmar que a forma definitiva de um sistema ainda em vigor foi consolidada?

${ }^{9}$ Estou usando esta expressão nos termos propostos por Slicher van Bath (1963 p. 21).

${ }^{10} \mathrm{O}$ ponto decisivo é que todo sistema produtivo baseado no escravismo possui uma produtividade baixa. Ele pode subsistir enquanto puder dominar pela força sociedades mais fracas, que lhe servirão como fonte de energia humana, que não pode ser gerada na própria sociedade escravista (cf. BLOCH, 1975, p. 247). No entanto, gerar somas
} 
oposta nas zonas baseadas no trabalho livre: o mercado "interno" em constituição era mais dinâmico e a economia muito mais variada. Era exatamente a crescente procura nestas regiões marcadas pelo trabalho livre que estimulava a especialização no restante da economia-mundo e, simultaneamente, cristalizava as formas compulsórias de trabalho nas margens do sistema.

Discutiremos logo à frente como estas articulações funcionavam. Resta, antes, desenvolver um pouco mais os padrões de reprodução do capital comercial em sua forma ideal. O capital comercial tentava fugir desesperadamente da reprodução do trabalho vivo. Isto fica mais nítido se olharmos para fora das, até então, raras regiões baseadas no trabalho livre. O servo e o escravo, que se integravam ao sistema a partir da periferia em constituição, eram um custo que ficava a cargo dos latifundiários, estes por sua vez, ficavam presos ao capital mercantil pelo fio do crédito e pelo fato dos mercadores controlarem as etapas finais da distribuição. O fornecimento de escravos transformou radicalmente a face atlântica da África: as tribos apresadoras de escravos, ao se especializarem na captura de cativos - preferencialmente trocados por cavalos equipados (sela, arreio e estribo) e armas de fogo - destruíram e rearranjaram grande parte das unidades políticas desta zona do continente, sedimentando poderosas forças descentralizadoras que se especializavam na guerra para, essencialmente, produzir escravos (ALENCASTRO, 2000; CURTIN 1995). Os cativos eram transpostos para os portos da costa ocidental africana e, a partir dali, rumavam para as Américas, para alimentar os engenhos e trabalhar nos latifúndios postos em marcha para suprir a demanda europeia. Todas as etapas eram mediadas pelo capital mercantil. Sua vitalidade derivava exatamente do fato de comandar de fora a produção e, também, por drenar indiretamente a população dos sistemas sociais africanos.

No entanto, quanto mais o capital comercial se reproduzia e ampliava a sua escala de operação, mas ele estimulava as diversas formas de produção distribuídas pela economia-mundo, respeitando as suas particularidades: a rede manufatureira nos países centrais e os latifúndios exportadores nas margens do sistema cresciam de forma diferente e obedeciam a padrões específicos, os quais tornavam possível a complementaridade. Em todos os casos, ao longo do tempo, ocorre um certo grau de acumulação "interna" nas zonas periféricas: isto é, uma parcela do capital comercial tende a ficar retida nas mãos de operadores de âmbito local. Esta

elevadas de capital mercantil nestas condições envolve outros requisitos: a elevação dos lucros só é possível mediante a ampliação da escala da produção e, sobretudo, do volume do mercado que, por motivos óbvios, deve ser externo à zona de produção escravista. No caso de Roma - o objeto das reflexões de Bloch - os escravos eram capturados pela máquina de guerra (ou por apresadores independentes, que os vendiam para o Império) e a produção do latifúndio (azeite, vinho, etc.) era redistribuída dentro do Império e em algumas redes de comércio de longa distância, um tipo de produção que não concorria com os pequenos produtores alodiais que viviam no entorno do latifúndio. No caso da escravidão colonial moderna, a produção escravista era escoada sobretudo para os mercados metropolitanos. 
parcela de capital é muito mais elevada nos países onde domina o trabalho livre, por conta da maior volume e integração do mercado e, consequentemente, uma maior penetração da sua lógica na estrutura social. Nas demais zonas da economia-mundo, a segmentação dos mercados e o primado da produção para exportação conferirá aos proprietários deste capital privilégios exorbitantes, que se materializam em uma tendência exagerada ao consumo conspícuo e à valorização da tradição. Se retirarmos o capital comercial de sua escala real - a economiamundo moderna em processo de consolidação, em conjunto com sua arena externa (Wallerstein) - o produto necessário é uma ilusão: a ideia de que a explicação sobre a Revolução Industrial repousa fundamentalmente no empreendedorismo e no grau elevado de poupança dos países centrais. Ou, então, a mesma ilusão, só que virada do avesso: a tese de que o fracasso do industrialismo nas ex-colônias e na Europa Oriental é fruto exclusivo da incompetência das elites locais em converter o capital comercial que ficava retido em suas mãos em capital industrial.

\section{A Europa Oriental ou as "Américas internas"}

A grande retração do século XIV detonou um conjunto de tensões que despedaçaram a sociedade feudal. Embora extremamente variadas, as diversas reações à crise se concatenaram ao processo geral de expansão da esfera da circulação, que caminhava a par com o processo de consolidação dos Estados modernos. A Europa Oriental, no século XVI, tomou uma via peculiar. A turbulência social típica dos séculos anteriores esmagou os pequenos senhores e enfraqueceu as cidades autônomas. Neste quadro, ao restringir o processo de centralização e burocratização do Estado, a nobreza conseguiu reforçar seus direitos e esmagar as rebeliões camponesas ${ }^{11}$. $O$ resultado foi o que se convencionou denominar segunda servidão: os laços servis foram progressivamente arrochados, fazendo com que os camponeses perdessem a capacidade de tomar decisões sobre o que plantar, ficando, portanto, à mercê dos "magnatas feudais"12.

\footnotetext{
${ }^{11}$ Esse aspecto é decisivo. A condição fundamental para o reforço da servidão é a preservação do poder local da nobreza, mais precisamente da grande nobreza, que massacrou os pequenos senhores e, portanto, reduziu a variação das forças sociais, muito mais pronunciada na França e Inglaterra, por exemplo. Este quadro social gerou formas estatais descentralizadas tais como o sistema de dietas, típico da Europa Oriental ou como as formas que se condensaram (seguindo determinações completamente distintas) nas zonas próximas aos núcleos das forças mais universais, isto é, do Papado e o Império.

${ }^{12} \mathrm{Na}$ alta Idade Média, as decisões econômicas estavam a cargo dos camponeses: eram eles que, comunalmente, no nível da Aldeia, decidiam o que e como plantar (na verdade, a decisão do que plantar era muito restrita: a agricultura medieval era baseada essencialmente no replantio). A nobreza, portanto, não comandava a produção: somente o fazia na reserva senhorial, nos poucos dias destinados à corveia. Para poder concatenar a produção camponesa aos mercados externos, o senhor teria de reforçar a corveia: isto é, elevar a pressão sobre os camponeses e destruir o caráter comunal da organização das Aldeias. Foi exatamente o que ocorreu na Europa Oriental. Logo, a segunda servidão foi um processo de transformação radical das antigas estruturas político-econômicas, e não apenas uma simples intensificação da coerção. A estrutura das aldeias e a própria relação entre a cidade - sob domínio dos magnatas feudais - e o campo mudou.
} 
Este processo entrou em conexão com a procura crescente da Europa Ocidental por alimentos e matérias primas. Ao vedar o acesso dos camponeses ao mercado, os grandes senhores feudais puderam se associar - de forma subordinada - aos mercadores dos grandes centros financeiros (Amsterdã, Gdansk etc.) e, por seu intermédio, exportar cereais, vinho, madeira e outros produtos para a porção ocidental do continente.

A chave está na articulação. Olhando apenas as relações de produção em sua dimensão local, não há praticamente nenhum elemento ou relação com o capitalismo comercial: os mercados locais são quase inexistentes, os produtores diretos são submetidos ao trabalho compulsório e, aparentemente, as zonas produtivas são isoladas. Mas não é o que ocorre: como salientou Braudel, as unidades econômicas baseadas na segunda servidão não são economias naturais pois são abertas "em cima": a produção, feita em maior escala, tem como destino um cliente longínquo, geralmente situado na Europa Ocidental. Mas o aspecto decisivo é que a conexão não é direta: há um intermediário, que empresta dinheiro ao grande proprietário, desloca a sua produção para o Ocidente e, simultaneamente, lhe oferta os produtos de luxo. Sem os adiantamentos provenientes dos grandes financistas, o nobre não pode continuar desempenhando o seu papel econômico e, também, teria de abrir mão de sua vida suntuosa. Está, portanto, preso ao capital comercial. É o magnata feudal que corre a maior parte dos riscos pois, de um modo geral, recebe um adiantamento pela produção futura. Isto protege o mercador-financista ${ }^{13}$ de uma eventual elevação abrupta dos preços e lhe permite, na prática, controlar à distância os grandes produtores. Os senhores precisam se adequar às exigências do mercador se quiserem renovar os seus adiantamentos e continuarem no negócio. O limite inferior é, exatamente, a necessidade de permitir que os camponeses reproduzam as suas famílias, para repor o estoque de trabalho vivo $^{14}$.

\footnotetext{
${ }^{13}$ Jan Luiten van Zanden prefere enfatizar o papel de uma das personificações do capital comercial, que ele denomina "mercador-empreendedor": "Capitalismo Mercantil é aqui utilizado para designar a fase em que no desenvolvimento do capitalismo onde o mercador-empreendedor dominava. $\mathrm{O}$ empreendedor combinava atividades comerciais com a intervenção no processo de produção e, portanto, nas relações de trabalho; embora as atividades comerciais (ainda) eram mais importantes do que aquelas. Isto o distingue dos mercadores nos modos de produção pré-capitalistas, que apenas compravam e comerciavam excedentes locais e formavam um lucro baseado nas diferenças regionais de preços. O mercador-empreendedor, em contraste, reorganizava a produção para criar excedentes que podiam ser comerciados. A fonte ostensiva de seus lucros era baseada na diferença entre os preços de compra e de venda dos produtos que ele trocava. (1993 p. 4). Trata-se, inevitavelmente, de uma das vias onde o capital mercantil se associou à produção, mas o mercador-empreendedor está em uma posição inferior ao grande mercador.

${ }^{14}$ Neste sentido, o magnata feudal é fundamentalmente diferente do senhor de engenho: ele não depende de uma fonte de trabalho externa (e isso lhe garante um grau de autonomia maior), mas, por outro lado, isto limita demais sua capacidade de crescimento: ele depende do padrão demográfico dos camponeses, o qual ele só pode influenciar positivamente se reduð̌ir o sen grau de exploração. Logo, as Américas, por serem constantemente nutridas por cativos capturados fora da economia mundo, exerceram um papel muito mais decisivo na acumulação primitiva de capitais.
} 
Privilegiar as conexões estabelecidas pelo capital comercial na escala da economiamundo não significa dissolver as especificidades locais. Muito pelo contrário: é este procedimento que evidencia as respostas diferenciadas a um mesmo movimento geral. A preponderância dos senhores sobre as cidades, o bloqueio da burocratização e a dissolução das aldeias em prol da reserva senhorial foi uma das diversas respostas possíveis à crise do feudalismo. Esta via possibilitou uma concatenação dinâmica entre o capital mercantil e a estrutura produtiva em transformação na Europa Oriental.

(...) But it does seems to me that the second serfdom was the counterpart of a merchant capitalism which discovered in the structures of Eastern Europe certain advantages and even in some cases its raison d'être. The great landowner was not a capitalist, but he was a tool and a collaborator in the service of capitalism in Amsterdam and elsewhere. He was part of the system. The mightiest landowner in Poland received advance payments from the merchant of Gdansk and trough him from the Dutch merchant (BRAUDEL, 1982, p. 271).

A posição do produtor frente ao detentor do capital comercial é, claramente, de inferioridade. Mas a sua situação não é tão frágil quanto, por exemplo, a posição dos pequenos produtores independentes rurais que também necessitam de adiantamentos. Ser poderoso em seus domínios - frente aos camponeses, frente aos raros mercadores locais e sobretudo ao Estado - é a condição para viabilizar este tipo de associação subordinada:

"He" - the feudal landlord - used his undisputed power to organize production in such a way as to meet capitalist demand - which only interested him in so far it balanced his own demand for luxury goods. (...) it was the western entrepreneur who had first come knocking at their door. But was the Polish noble who had the power - as he amply demonstrated - to set all the peasants and a good number of the towns to work for him, to dominate agriculture and even manufacture, virtually the whole of production in other words. When he mobilized all this power in the service of foreign capitalism, he was himself becoming an active participant in the system. If it had not been for him, there would have been no second serfdom; and without serfdom, the volume of exportable cereals produced would have been infinitely smaller. The peasants would have preferred to eat their own grain, or to exchange it on the marketplace for other goods, if the nobleman had not taken over all the means of production and if, by the same token, he had not nipped in the bud an already lively market economy, thus 
keeping for himself all the means of exchange as well. (BRAUDEL, 1982, p. $271-2)^{15}$.

A rede de relações é nítida: o encolhimento dos mercados locais e a projeção para o mercado externo - onde o magnata feudal fica preso aos tentáculos do capital comercial - são o produto do contato entre as condições específicas da Europa Oriental e o capitalismo comercial em expansão na economia-mundo.

A autonomia do capital comercial repousa, fundamentalmente, na sua capacidade de articular pelo alto diversos subsistemas regionais, com formas de produção e de existência do trabalho distintas, os quais, exatamente por conta de sua conexão com a o capital mercantil, ou melhor, pela sua pressão, tendem a acirrar a sua lógica básica. Em outros termos, o capital mercantil é capaz de mobilizar - e intensificar - sistemas de exploração preexistentes ${ }^{16}$. No caso que ilustramos, fica claro que a segunda servidão não se arraigaria tanto sem um conjunto de circunstâncias: i) a pressão da demanda na Europa Ocidental que ampliava a pequena produção e as manufaturas; e, portanto, abrigava um grande número de pequenos produtores independentes e assalariados, que passaram a se socializar predominantemente pelo mercado; ii) a disponibilidade de crédito nas mãos do grande mercador (e seu conhecimento das "necessidades" cruzadas das diversas elites (inclusive as que se situavam fora da civilização cristã)); iii) o reforço do poder local dos senhores na Europa Oriental ${ }^{17}$. A tradição sobrevive, reformulada, na Europa Oriental. O magnata feudal abriu a porta ao mercador ocidental pois queria reforçar ainda mais a sua distinção social, expandindo o seu acesso aos bens de luxo e à ociosidade. Para tanto, usou seus privilégios para monopolizar os meios de produção e, deste modo, se esforçava para expandir a produção exportável sem se preocupar com a elevação da produtividade mediante inovações ou uma administração racional dos insumos. Contribuiu, portanto, ao seu modo e sem saber, para transformar o regime de produção nas regiões que, no futuro, ocuparam o centro da economia-mundo.

\footnotetext{
15 O quão "bem viva" era - ou poderia ser, sem a pressão senhorial - esta economia de mercado é algo bastante discutível, principalmente na Polônia e nas demais zonas da "segunda servidão". Mais uma vez transparece a ideia de um desenvolvimento "natural” ou espontâneo do mercado na reflexão de Braudel.

${ }^{16}$ Essa intensificação pode ser engendrada de forma direta e indireta. No primeiro caso, ao aumentar a demanda por um dado produto, favorece a ampliação da escala de operação e a intensificação da exploração, como ilustra a já aludida conexão entre as plantations e o apresamento de cativos na África. No segundo caso, ao aguçar ainda mais o já insaciável apetite por luxo dos privilegiados, desdobram-se algumas tendências (que podem, dentro de certos limites, se combinarem): i) aumentar a escala das atividades "econômicas" (plantations, a pressão da nobreza para expandir a reserva senhorial e a corveia, extensão das redes de putting-out, etc.); ii) expansionismo territorial; iii) elevação da pressão - e da racionalização das formas de exploração - sobre as fontes de trabalho que já estão ao seu dispor. Das três, a mais imediata é esta última.

17 "Uma conjuntura com efeitos duplos ou triplos impeliu, no início do século XVI, a Europa oriental para um destino colonial de produtor de matérias-primas, destino que a segunda servidão é apenas o aspecto mais visível" Ibid p. 232.
} 


\section{$\mathrm{O}$ antigo sistema colonial}

$\mathrm{Na}$ Europa Oriental a rede mercantil penetra na produção camponesa indiretamente, através de uma associação entre o grande mercador e o senhor local que, pelo menos em seu início, foi voluntária. Não foi o que ocorreu na outra ponta da Economia-mundo moderna. O vínculo entre o capital mercantil autônomo e o Sistema Colonial do Antigo Regime é muito mais profundo por conta do modo como as Américas foram incorporadas à economia-mundo. A rivalidade política entre as monarquias absolutistas na Europa Ocidental favoreceu a propensão à mercantilização crescente da produção. O processo de centralização e burocratização do Estado multiplicava a necessidade de tributos; convertendo este aparelho em um potencial indutor do desenvolvimento da economia mercantil em escala "nacional": no caso da França, por exemplo, a concessão da propriedade aos camponeses rompeu com as fontes diretas de rendimento da nobreza, dinamizou os mercados locais e, simultaneamente, converteu-se em uma fonte importante de impostos. A generalização do papel-moeda "territorial" (mais popularmente - e imprecisamente - qualificada como "nacional") e o desenvolvimento dos transportes facilitou a integração dos mercados que, anteriormente, além de atrofiados, não se comunicavam ${ }^{18}$. Neste novo ambiente as cidades passaram a intensificar a sua especialização no comércio e na produção artesanal ou manufatureira ${ }^{19}$.

\footnotetext{
${ }^{18}$ Esse aspecto é fundamental. O mercado local e o de longa distância não se comunicavam diretamente: eram sujeitos a mecanismos distintos e envolviam classes diferentes. Os mercados locais envolviam a produção que ultrapassava a subsistência dos produtores $e$ a parcela da produção açambarcada pela nobreza e pelo Estado. O mercado de longa distância dependia por sua vez da capacidade de exploração das classes dominantes (deduzindo seus custos de reprodução). Logo, como os ganhos de produtividade eram pequenos, estes mercados são inversamente proporcionais: para expandir o seu acesso ao consumo suntuoso, as classes parasitárias precisam elevar os niveis de exploração, fato que reduz o volume dos mercados locais e pode comprometer até mesmo a possibilidade de subsistência dos camponeses, como efetivamente ocorreu no século XVI. Essa contradição não foi percebida na expansão que se seguiu à crise do século XIV porque a economia estava crescendo em termos absolutos (elevação da população camponesa, seguida do arroteamento de terras e multiplicação das aldeias). Carlo Cipolla aponta $o$ biato entre estes dois mercados: "Uma mistura curiosa de universalismo e particularismo dominava a cena. Era economicamente vantajoso obter sedas preciosas da China ou tapetes preciosos do Oriente Próximo, mas não era usualmente vantajoso obter mercadorias mais simples a poucas milhas de distância. Como os transportes em massa eram impossíveis por razões técnicas, o custo dos fretes permanecia relativamente elevados. Particularmente quando o transporte por via aquática era impossível, o comércio de longa distância tinha de basear-se principalmente, senão exclusivamente, em objetos preciosos. Para as suas necessidades diárias básicas qualquer comunidade tinha de ser o mais autossuficiente e autossustentável possível. A divisão interlocal do trabalho tinha de repousar em artigos preciosos ou em outras coisas que não podiam ser produzidas localmente ou que não pudessem ser substituídas de forma simples por outros produtos. E o comércio tinha de sustentar-se fortemente no consumo aristocrático de mercadorias suntuosas" (1967 p. 57).

19 Além disto, em um Estado mais burocrático e centralizado, o papel da nobreza é distinto. Ela mantém seus privilégios principalmente no plano da isenção fiscal e na maior facilidade de integrar-se à burocracia em expansão (diferente de seus pares nas versões mais descentralizadas, típicas da zona da segunda servidão, que preservaram o seu poder local e, portanto, não ficaram submissas ao poder central, preservando a capacidade de usar a violência direta contra o trabalho). Neste sentido, o fortalecimento do Estado ao qual pertencem é do interesse da nobreza em geral, por mais que esse reforço do poder central possa ser percebido negativamente por grupos e interesses
} 
A expansão do capital mercantil ocorre, portanto, mediante uma tensa relação com os Estados em formação. A partir de 1450, quando as fronteiras na Europa começam a se definir, o acesso ao ouro e metais preciosos era decisivo: os mercenários, o principal tipo de combatente, só podiam aceitar este tipo de pagamento, pois tinham de manter a sua autonomia frente a realeza, a partir de então, os seus principais clientes ${ }^{20}$. Isto abriu uma possibilidade adicional ao grande mercador: emprestar recursos às casas reais (que, para pagar, elevavam os impostos e lutavam para expandir seus domínios (TILLY, 1996). Os Estados que triunfavam com mais regularidade nos conflitos tendiam a "alavancar" crédito com mais facilidade. A situação era adversa para os Estados então mais frágeis, que eram obrigados a contrair empréstimos mais caros e, também, buscar um sistema de alianças que garantisse a sua sobrevivência, mas que, em contrapartida, reduzia a sua soberania ${ }^{21}$.

Como era muito mais difícil avançar territorialmente sobre os rivais diretos - as monarquias em formação - a tendência foi buscar pontos de apoio fora da Europa. A forma de ocupação dependia de alguns fatores interligados: i) a relação de forças entre o conquistador europeu e a zona a ser colonizada; ii) a

particulares dos nobres, tomados isoladamente (ANDERSON, 1974 p. 22-41). Quanto mais próspero o aparelho estatal, mais cargos e privilégios a Coroa pode oferecer. Além disto, os nobres que vivem prioritariamente dos arrendamentos, por sua vez, possuem também um interesse na vitalidade do mercado nacional: a prosperidade dos farmers possibilita a elevação do valor dos aluguéis. É, portanto, possível a convivência harmoniosa entre a nobreza e uma burguesia nacional nascente (pelo menos até a maturação das contradições que desencadeará, no futuro, as "revoluções liberais"). Os magnatas feudais da Europa Oriental, por outro lado, tinham como interesse sufocar ou controlar os mercados locais e regionais para destinar para fora a maior parcela possível da produção nacional. Sua força repousava, exatamente, na debilidade relativa do aparelho de Estado e em seu controle violento sobre a terra e o trabalho (cf. BRAUDEL, 1982. p. 232-3).

${ }^{20}$ De acordo com um brilhante artigo de Victor Kiernan (1957), a prata era a principal forma de pagamento. Os mercenários eram provenientes de zonas características, onde o poder central era frágil (diversas regiões montanhosas da Suíça e da atual Alemanha, Gasconha, Gales, Córsega e até mesmo dos Balcãs, dentre outras regiões). O Rei, por controlar mais recursos, tinha uma capacidade maior de contratar mercenários do que a nobreza local potencialmente rebelde (fato que estimulava a luta da realeza pela expansão fiscal). Por outro lado, os mercenários estrangeiros defendiam tanto a nobreza quanto o Rei dos frequentes levantes populares do século XVI. A Guerra dos 30 anos, por exigir um volume considerável de combatentes e uma hierarquia mais rígida, consolidou os mercenários como um apoio quase exclusivo da Coroa. Kiernan não deixa de notar uma ironia: os mercenários eram amantes da liberdade e, por conta disto, resistiram a ser subjugados diretamente pela Coroa (por isso buscavam refúgio nas zonas montanhosas e se mesclavam às comunidades rurais). Foram forçados a recorrer inicialmente às pilhagens (o "banditismo", na discussão clássica sobre a formação do Estado) e, dominantemente, a lutar por dinheiro. Com a consolidação de algumas burocracias mais poderosas, eles ajudaram a consolidar os Estados absolutos, reprimindo as revoltas populares e derrotando nobres rebeldes.

${ }^{21} \mathrm{Um}$ aspecto importante a ser notado é a conexão entre a concentração política e econômica típica do período. Os Estados ascendiam em conjunto com os seus principais credores, formando um sistema de retroalimentação. Por outro lado, a derrota de um Estado em uma guerra importante poderia implicar na falência dos seus credores principais ou, pelo menos, em perdas significativas (que poderiam ser compensadas com a associação a um mercador mais poderoso). Logo, a formação de um cenário político marcado por um número restrito de Estados centrais ocorreu, portanto, em sincronia com a concentração de recursos nas mãos de uma casta cada vez mais reduzida de grandes mercadores. Além disto, a relação entre a Coroa, os mercenários e os credores não era direta: entre eles foi se constituindo a figura do "empresário militar", fato que favorecia ainda mais a generalização das operações de crédito: tanto o Rei quando estes empresários tendiam a tomar créditos dos grandes mercadores (Cf. WALLERSTEIN, 1974 p. 140-1). 
preexistência ou não de circuitos mercantis que pudessem ser conectados ao comércio de longa distância europeu; iii) as condições geográficas do território (o sistema de ventos e de correntes, a integração entre a zona terrestre e os sistemas fluviais, etc.). Geralmente, onde a resistência ao conquistador era maior, e existiam redes comerciais, a tendência foi a instalação de feitorias na ponta final destas redes, com o objetivo de vedar o acesso dos concorrentes europeus às mercadorias ali transacionadas. A partir destas guarnições, era possível estabelecer uma relação simbiótica com os poderes e os mercadores locais (as tribos africanas que apresavam escravos, por exemplo). O investimento em capital fixo é mínimo e os custos de defesa (contra os rivais europeus) são, deste modo, cobertos pela posição monopolista no mercado europeu. Onde a resistência era menor, via de regra, as redes comerciais eram menos densas ou, até mesmo, inexistentes. Em termos relativos, era fácil conquistar tais territórios, mas a sua manutenção exigia muito mais investimento: envolvia a organização de um sistema produtivo capaz de, mediante o trabalho compulsório, gerar, também de forma monopolista, produtos demandados no sistema comercial europeu.

Em todos os casos, quer nas colônias, quer nas feitorias, o capital mercantil é que articulava os diversos circuitos econômicos, evitando ao máximo penetrar na produção. Entretanto, nas colônias de exploração, ele foi compelido a ir além de seus limites, organizando a produção nas novas zonas conquistadas pelos europeus, tendo como um dos seus objetivos, fortalecer o Estado metropolitano pela via da circulação, envolvendo predominantemente a produção de gêneros tropicais e o acúmulo de metais nobres. Logo, com vistas a atender esta finalidade, o Antigo Sistema Colonial se estruturou em torno de três elementos fundamentais: 1) a dominação política, nas suas mais variadas formas e graus; 2) o regime de comércio assimétrico (cujo arquétipo é o exclusivo metropolitano), que fundamentava a transferência de renda líquida da colônia para a metrópole e 3) preponderância do trabalho compulsório, num espectro que ia da servidão ao escravismo (NOVAIS, 2007). Desse modo, a economia colonial não era capaz de se reproduzir de forma autônoma, pois o circuito do capital era concluído no mercado europeu, as decisões políticas fundamentais eram tomadas na metrópole e, por fim, nas regiões onde o trabalho compulsório atingia o limite, não havia sequer reprodução interna da força de trabalho.

\section{Capital mercantil e estratificação social}

Do ponto de vista dos grandes mercadores, portanto, a arquitetura do Antigo Sistema Colonial se adequava perfeitamente ao seu padrão de investimentos: diversificação, preponderância de inversões ligadas à agilização da circulação e, sobretudo, a possibilidade de retorno rápido à liquidez. Esta versatilidade era possível porque os investimentos em capital fixo e a maior parte dos riscos ficam a 
cargo dos colonos, fato que concentrava nas mãos de um punhado de mercadores baseados na Europa a maior parcela do cobiçado capital comercial. Logo, tratavase de uma articulação muito mais rígida do que a conexão estabelecida na Europa Oriental, a qual, como vimos, contou com a anuência dos senhores locais e, deste modo, era de controle muito mais indireto. Com o ciclo de independências que resultou da crise do Antigo Sistema Colonial, a posição dos ex-colonos se aproximou à dos magnatas feudais, principalmente depois das pressões britânicas contra o tráfico negreiro, que exigiram uma mudança na forma de trabalho ou, como no caso dos EUA, a reprodução interna da escravidão. Logo, neste quadro, a metamorfose do capital comercial em industrial gerou, em um primeiro momento, uma homogeneização relativa das antigas periferias que, em seu conjunto, passaram a gravitar em torno da nova ordem comercial progressivamente arbitrada pela Grã-Bretanha, pautada predominantemente pelo imperialismo do comércio livre.

Do que foi discutido, é possível apontar as relações entre o capital mercantil e a estrutura social, na fase de consolidação do capitalismo. O contato efetivo entre o capital comercial e a produção era estabelecido pelos setores intermediários da sociedade ${ }^{22}$, usualmente denominados - de forma pouco precisa - como pequena e média "burguesia". Um grupo muito heterogêneo, mas que tinha em comum a subordinação à simbiose estabelecida, no longo século XVI, entre os ricos comerciantes, a aristocracia e a burocracia dos Estados. Quanto mais estes setores intermediários se desenvolviam, mais abrangentes e sistemáticos se tornavam os vínculos entre o capital mercantil e a produção, fato que acabou, dentro de diversas outras determinações, por possibilitar a maior penetração das relações mediadas pelo mercado na sociedade e a emergência do capital industrial. Afinal, o interesse imediato em elevar a produtividade do capital fixo vinha dos setores sociais imediatamente abaixo do círculo de privilegiados que gravitava no entorno do capital mercantil. No entanto, salientar isto não implica em aderir ao mito do "Burguês Herói", em suas várias expressões ${ }^{23}$. Isto é particularmente nítido no caso da Grã-Bretanha, onde a ofensiva cobdenita pretensamente radical contra a "velha corrupção" refluiu rapidamente, na exata medida em que a importância da riqueza comercial e financeira aumentava, principalmente por conta da industrialização que remodelou mas, simultaneamente, acentuou as formas de privilégio típicas da sociedade britânica (CAIN; HOPKINS, 1993, p. 17-34). Quanto mais longe da

\footnotetext{
22 Wallerstein, chamou a atenção para isto. Ao comentar os cercamentos, por exemplo, ele nota que, na Inglaterra e na Espanha do século XVI, não eram os grandes proprietários - porque tiravam proveito ainda da "velha ordem feudal" - que tinham interesse em cercar, mas sim os pequenos produtores independentes (1974, p. 108-9). Um raciocínio similar é feito por Hobsbawm (1954), ao sugerir, em diversos pontos de sua obra, que a Revolução Industrial foi gestada por setores intermediários, que não tinham prestígio e nem dinheiro suficiente para se situar no patamar dos grandes mercadores.

23 Infelizmente esse mito persiste na esquerda: como se houvesse algum setor da burguesia inerentemente "progressista" ou, para dizer o mesmo de forma mais explícita, acomodar-se em torno de um fatalismo: se o parasitismo é inevitável, a luta deve se direcionar para escolher qual parasita é menos nocivo ao conjunto.
} 
produção, maior o prestígio. Logo, o status da burguesia industrial não era dos melhores. Para consolidarem a sua posição, eles tinham de penetrar no restrito círculo da nova fidalguia, que aprendeu a combinar as suas formas de vida com a rentabilidade do seu patrimônio (cujos laços sociais eram um componente decisivo, e envolviam um código social bastante curioso, fundado na fusão entre a Honra e o Dever [obligation], mas temperado com resquícios do amadorismo nobiliárquico). Logo, a finança apoiada na elevação das forças produtivas proporcionada pela indústria recriou e intensificou os monopólios sociais. Mas isto, é claro, situa-se em outro período, onde o capital mercantil já perdeu a sua centralidade e seu irmão gêmeo, ao subordinar progressivamente o capital industrial, estava conquistando a primazia.

\section{Capital comercial, acumulação primitiva e a autonomização da "esfera econômica"}

Não resta dúvida que, à primeira vista, a autonomização da "esfera econômica" é um aspecto fundamental e distintivo do capitalismo e que, para ficarmos no sintético plano da lógica, isto só se consolida mediante dois movimentos. Em primeiro lugar, é fundamental a separação entre o trabalho e os meios de produção que, em essência, impõe a mediação do mercado sobre as etapas essenciais da produção social da vida. O segundo aspecto, que não deriva necessariamente do primeiro, mas que, por assim dizer, completa a transição, é a consolidação da indústria moderna, isto é, a "Revolução Industrial", na medida em que ela possibilita a generalização crescente da concorrência capitalista na vida social e, fundamentalmente, abre o caminho para o predomínio do capital financeiro, onde o capitalista se sente realmente em casa, para retomar uma imagem sugerida por Fernand Braudel. Mas este resultado não é fruto de nenhum tipo linear de acumulação, seja ela econômica ou "política". Isso fica muito claro na discussão marxiana sobre a "acumulação primitiva", que é essencialmente descontínua, marcada por temporalidades múltiplas e que só faz sentido tendo como referência a dinâmica "pura" do capitalismo consolidado. Trata-se, portanto, de uma abordagem nutrida fundamentalmente pela História, mas que retrata o processo de constituição do capitalismo não como história da sua formação mas, essencialmente, como gênese de elementos ${ }^{24}$.

\footnotetext{
${ }^{24}$ Cf. Etienne Balibar (1980). Reconstruir a história da formação exige partir da concepção do feudalismo como um modo de produção, isto é, dotado de contradições internas e uma dinâmica própria, que faz precipitar e conduz a sua crise, mas não determina por si só o resultado final: a consolidação do capitalismo. Exatamente por tratar-se de uma transição, a passagem do feudalismo ao capitalismo não foi inevitável (a ênfase na necessidade da passagem explica-se muito mais por motivos de tática política - a alegada inevitabilidade do socialismo como sucessor do capitalismo do que por razões intelectuais).
} 
Privilegiamos aqui as características gerais e os circuitos do capital mercantil, apontando o modo como ele foi penetrando na vida social da economia-mundo em constituição. Partimos do seu vínculo mais explícito, isto é, com o processo de formação do Estado moderno. Em diversas escolas do pensamento é cada vez mais frequente a ênfase no papel fundamental que a formação de um sistema interestatal que combina - de forma variável, mas recorrente - a rivalidade política à econômica exerceu neste movimento geral. A rivalidade interestatal, dentre outros efeitos, vinculou o capital comercial à construção do monopólio da violência e ao sistema da dívida pública e, desse modo, favoreceu a alteração das formas e do papel do financiamento da atividade econômica, fato que aumentou tremendamente o poder das classes detentoras de grandes volumes de capital em forma líquida e, desse modo, favoreceu a vinculação das demais formas de prestígio à mobilidade social baseada na riqueza $a^{25}$.

Mas algumas barreiras importantes - e mais difíceis de serem visualizadas diretamente - precisaram ser derrubadas. A consolidação do capitalismo envolveu também a dissociação - antropólogos e sociólogos tendem a usar o termo "desencravamento" - da função do comerciante de um grupo de status predefinido dentro da hierarquia de prestígio social e/ou da tutela direta do Estado:

Dois casos mereceriam um exame atento. O primeiro é dos comerciantes e dos "capitalistas" indianos. O sistema de castas reconhece neles uma identidade claramente definida, autorizando-os a enriquecerem o quanto desejarem e puderem. Eles aliás não se privam disso. Mas o campo que assim lhes está aberto, ao mesmo tempo constitui um freio que os mantém dentro do sistema de castas, impedindo que se transformem em classe. Por mais ricos que se tornem, jamais poderão ultrapassar o nível de prestígio que a priori lhes é atribuído na hierarquia da impureza. Jamais poderão igualar-se lendariamente aos brâmanes ou aos xátrios. O outro caso é o dos povos comerciantes, cuja existência parece quase universal. Nos sistemas de trocas internacionais mais primitivos veem-se realmente surgir tribos especializadas no comércio. Essa especialização é complementar à de outras tribos na pesca, na agricultura ou no artesanato. O que caracteriza esses sistemas de troca internacional arcaico é que visam manter um certo equilíbrio entre as diversas especializações, cujo

\footnotetext{
${ }^{25}$ Um dos traços distintivos do Antigo Regime é a tensão entre o caráter estamental persistente e uma estratificação em classes que floresce preponderantemente dentro do Terceiro Estado, em torno da riqueza e das novas atividades econômicas (cf. NOVAIS, 2005 p. 199-200). O século XVI foi marcado por uma verdadeira luta de boa parte da nobreza para eliminar os impedimentos formais - a "tradição" - às ocupações comerciais e gerenciais e, quando tinham força para tanto, a resistência dos camponeses. (Cf. WALLERSTEIN, 1974 p. 157-162). Viver no entorno do Rei - a nobreza palaciana, que abdica das armas e da dominação local direta - para viver na Corte também era uma "traição" aos princípios da nobreza, frequentemente denunciado pelo minguante setor da nobreza apelidado a posteriori de "tradicional", que via a gestão dos negócios e a fidelidade ao Rei como uma renúncia da liberdade e do amadorismo, os elementos genuinamente constitutivos da fidalguia. É este tipo de nobreza que, percebendo que seu mundo iria desaparecer, desesperadamente tentou promover as fracassadas "reações feudais".
} 
sentido é aliás, mais 'cultural' que funcional ou propriamente econômico. A modernidade poderá ser interpretada como resultado de uma dupla liberação. Por um lado, liberação da lógica que mantinha as tribos comerciantes num determinado ponto da divisão do trabalho do conjunto. Daí por diante todas as funções serão subordinadas à função comerciante. E, finalmente, liberação do simbolismo, que limitava a posição social potencial dos comerciantes. Doravante eles poderão esperar ter acesso ao maior prestígio (CAILLÉ, 1989 p. 118).

A mercantilização crescente da vida social - alvo de diversas condenações morais e "reações civilizacionais" (sic.) - é fruto, portanto, de um duplo processo: a violenta conversão do trabalho em mercadoria que culminou na industrialização e o estilhaçamento das reações morais e simbólicas ao avanço do mercado, ou, mais precisamente, de uma classe cujo orientação fundamental e fonte primária de poder é a capacidade de acumular capital.

\section{Conclusão}

Para concluir, é necessário precisar melhor o que estou apontando como "autonomização" da esfera econômica: ela não é autônoma no sentido de prescindir ou de determinar diretamente as demais esferas da existência social ${ }^{26}$. A autonomização deve ser entendida no sentido preciso de ocupar um papel central na articulação do modo de produção (da vida), ou, em outros termos, no capitalismo é a "economia" que estabelece o nexo central que estrutura e dá unidade a um modo de produção (NOVAIS, 2005). Logo, se entendermos este conceito de forma ampliada - como modo de produção da vida, no estilo da reflexão presente em A Ideologia Alemã - é possível traduquir para a problemática marxiana elementos das tentativas desesperadas de se tentar criar, por intermédio de um método dito "comparativo", uma explicação alternativa ao marxismo sobre a formação do capitalismo. O ponto fundamental é que o modo de produção capitalista eliminou ou deslocon para os bastidores as formas mais tradicionais de controle da sociedade sobre o "mercado" (ou, mais precisamente, sobre os meios de produção), tais como, por exemplo, os sistemas redistributivos, a religião e a magia, ou as estruturas de parentesco ${ }^{27}$. Examinar os mecanismos e as formas de

\footnotetext{
${ }^{26}$ A esfera econômica precisa do apoio ou, pelo menos, da harmonização de instituições e processos que se situam "fora" de seu âmbito, tais como, por exemplo, o Estado e suas instituições formais, sistemas ideológicos e de aprendizado etc.

27 E aqui há uma longa e vigorosa bibliografia, com pontos de partida muito distintos (Richard Thurnwald/Malinowsky, Marcel Mauss, Tönnies, Polanyi, Clastres, Gluckman, Levi-Strauss etc.), mas que, recentemente, tendeu a se agrupar na antropologia econômica e, em menor grau, na macrosociologia histórica. Este vasto e heterogêneo campo temático converge em um aspecto fundamental: salientar a diferença essencial entre a sociedade de mercado - apoiada na miragem do indivíduo atomizado - gestada pelo capitalismo e as sociedades
} 
reprodução do capital mercantil e, essencialmente, tentar apontar as vias com que ele conseguiu penetrar na sociedade é uma das possibilidades para tentar dar alguma coerência a esta transformação singular.

\section{Referências}

ALENCASTRO, Luis Felipe de. O Trato dos viventes: formação do Brasil no Atlântico Sul. São Paulo: Cia. das Letras, 2000.

ANDERSON, Perry. Lineages of the absolutist state. London: New Left Books, 1974.

BALIBAR, Etienne. Sobre os conceitos fundamentais do materialismo histórico. In: ALTHUSSER, Louis (Org.) Ler o Capital, vol. 2. Rio de Janeiro: Zahar, 1980.

BLOCH, Marc. Slavery \& serfdom in middle ages: selected essays. Berkeley: University of California Press, 1975.

BRAUDEL, Fernand. Civilization and capitalism: 15th to 18 th century - the wheels of commerce. London: St. James Place, 1982.

CAILLÉ, Allain. A dominância do mercado. In: LACOSTE, Yves (Org.) Ler Braudel. Campinas: Papirus, 1989, p. 97-135.

CAIN, Peter; HOPKINS, Anthony. British imperialism: innovation and expansion, 1688-1914. London: Longman, 1993.

CIPOLLA, Carlo Money, prices and civilization in the Mediterranean world: fifth to seventeenth century. Nova York: Gordian Press, 1967.

anteriores, onde o mercado, se existente, estava subordinado a instituições políticas, mágicas ou de parentesco e muito raramente conseguia ocupar um papel importante na sociedade. A despeito de sua ampla variedade, há um procedimento básico por detrás deste estilo de pensamento: reconstituir a dinâmica de diversas comunidades e sociedades ao longo do tempo, para demonstrar a peculiaridade e a limitação da própria ideia de um homo economicus. Curiosamente, ao proceder deste modo, outro problema potencial ressurge: uma forte tendência a mitigar as diferenças entre as sociedades "primitivas" e "civilizadas" que, embora seja pertinente, de forma colateral, pode desembocar na suposição de que há uma identidade fundamental no homem. Polanyi identificou claramente esta tendência (cf. POLANYI, 1971b p. 65-7), mas nunca foi capaz de se libertar dela. Após reivindicar a importância do estudo sistemático das sociedades primitivas para iluminar a sociedade contemporânea, apontando as suas semelhanças, ele afirma: "Se qualquer conclusão pode ser destacada com mais clareza que as outras, no estudo recente das sociedades primitivas, é justamente a não modificação do homem como ser social. Seus dotes naturais reaparecem com uma constância marcante nas sociedades de todos os tempos e lugares e as precondições necessárias para a sobrevivência da sociedade humana parecem ser as mesmas, sem mutações” (POLANYI, 2000 p. 65). 
CURTIN, Peter. The rise and fall of the plantation complex. Cambridge: Cambridge University Press, 1995.

CURTIN, Peter. Cross-cultural trade in world history. Cambridge: Cambridge University Press, 1984.

HOBSBAWM, Eric. The general crisis of the European economy in the XVII century. Past and Present, N. 5, 1954, p. 33-52.

KIERNAN, Victor. Foreign mercenaries and absolute monarchy. Past and Present, (11) 1, 1957, p. 66-86.

KRIEDTE, Peter. Peasants, Landlords and merchants capitalists: Europe and the world economy, 1500-1800. Cambridge: Cambridge University Press, 1984.

MARX, Karl. O Capital: crítica da economia política, tomo V. São Paulo: Nova Cultural, 1988a.

MARX, Karl. O Capital: crítica da economia política, tomo IV. São Paulo: Nova Cultural, 1988b.

MARX, Karl. Capítulo VI inédito de 'O Capital': resultados do processo de produção imediata. São Paulo: Ed. Moraes, s.d.

MENDELS, Franklyn. Proto-industrialization: the first phase of the industrialization process. The Journal of Economic History, 32 (1), 1972, p. 241-61.

MERRINGTON, John. Town and country in the transition from feudalism to capitalism. New Left Review, N. 93, 1975.

NOVAIS, Fernando. Estrutura e dinâmica do antigo sistema colonial (séculos XVI-XVIII). Campinas: Instituto de Economia, 2007.

NOVAIS, Fernando. Aproximações: estudos de história e historiografia. São Paulo: Cosac Naiyf, 2005.

POLANYI, Karl. A grande transformação. Rio de Janeiro: Campus, 2000.

POLANYI, Karl. Ports of trade in early societies. In: DALTON, George (Org.) Primitive, archaic and modern economies: essays of Karl Polanyi. Boston: Beacon Press, 1971a, p. 238-260. 
POLANYI, Karl. Our obsolete market mentality. In: DALTON, George (Org.) Primitive, archaic and modern economies: essays of Karl Polanyi. Boston: Beacon Press, 1971b, p. 59-77.

SLICHER VAN BATH, Bernard. The agrarian history of Western Europe, Ad. 500-1850. New York: St-Martin's Press, 1963.

TILLY, Charles. Coerção, capital e estados europeus. São Paulo: Edusp, 1996.

WALLERSTEIN, Immanuel. The modern world-system: capitalist agriculture and the origins of the European world-economy in sixteenth century, vol. 1. Nova York: Academic Press, 1974.

ZANDEN, Jan Luiten van. The rise and decline of Holland's economy. Manchester: Manchester University Press, 1993.

Endereço para correspondência:

Eduardo Barros Mariutti - eduardomariutti@gmail.com

Rua Pitágoras, 353 - Barão Geraldo

13083-857 Campinas/SP, Brasil 